\title{
SURVAI DASAR GIZI DAN KESEHATAN DI WILAYAH KERJA WORLD VISION INDONESIA DAN WAHANA VISI INDONESIA DI KABUPATEN MERAUKE
}

\author{
(Nutrition and health baseline survey in ADP-WVI area Merauke District) \\ Lindawati Wibowo ${ }^{1 *}$, Otte Santika ${ }^{1}$, dan Markus Puthut Harmiko \\ ${ }^{1}$ SEAMEO-RECFON Regional Centre for Food and Nutrition, Jakarta, Indonesia \\ ${ }^{2}$ World Vision Indonesia
}

\begin{abstract}
This survey was conducted to estimate levels of health and nutrition problems as well as the associated factors among under-five children in the Area Development Program of World Vision Indonesia and Wahana Visi Indonesia in Merauke district. As many as 30 Posyandus were randomly selected as the cluster units where the information was collected among children $U-5$ and their mothers $(n=542)$. From this survey we estimated the prevalence of underweight, stunted, wasted, and anemic children were 11.7\%, 21.0\%, 7.5\%, and 73.7\% respectively. It was assumed that these nutritional problems were associated with several factors such as: family income, mother's literacy, knowledge and practices of mothers on health and nutrition, as well as the existing nutrition and health program implementation. This survey concluded that the nutrition problems in the study site were categorized as a public health concern. Thus, as the recommendations, two strategies to alleviate the local nutrition and health problems were proposed: direct and indirect. The direct approach is mainly focus on the improvement of existing nutrition and health programs (i.e. GMP, high dose vitamin A program, promotion of proper child feeding, etc.) implementation. Prior to that, a health system review must be carried out to identify the presence and functioning of the essential system components. Indirectly, a program need also to be carried out through multisectoral and community participation based on the government's leadership for the sake of alleviating poverty and illiteracy as the major underlying factors of malnutrition.
\end{abstract}

Key words: malnutrition, children underfive years, anemia, quality of heath service, Merauke

\begin{abstract}
ABSTRAK
Penelitian ini bertujuan untuk menilai besaran masalah gizi dan kesehatan serta faktor-faktor yang mempengaruhinya di wilayah kerja World Vision Indonesia dan Wahana Visi Indonesia di Merauke. Sebanyak 30 posyandu dipilih acak sebagai unit klaster. Pengumpulan data dilakukan pada ibu balita $(n=542)$ di unit klaster terpilih. Hasil penelitian menunjukkan estimasi prevalensi balita dengan berat badan kurang, pendek, kurus, serta menderita anemia berturut-turut adalah 11.7\%, 21.0\%, 7.5\% dan 73.7\%. Masalah ini diasumsikan terkait dengan beberapa faktor seperti: pendapatan keluarga, tingkat literasi pengasuh, pengetahuan dan praktik pengasuh yang berkaitan dengan gizi dan kesehatan, serta implementasi program gizi dan kesehatan. Penelitian ini menyimpulkan bahwa kasus kurang gizi masih tergolong permasalahan kesehatan masyarakat. Sebagai rekomendasi, disarankan untuk menjalankan dua strategi secara paralel yaitu 1) dengan mengoptimalkan program-program yang sudah berjalan seperti pemantauan status gizi di posyandu, program suplementasi vitamin A, pencegahan dan pengendalian penyakit, dan promosi pemberian ASI dan MP ASI dengan didahului oleh review sistem kesehatan agar diketahui komponen sistem yang mana yang perlu penguatan, 2) melalui kerjasama lintas sektor dan melibatkan partisipasi masyarakat bersama-sama dengan pemerintah untuk mengentaskan kemiskinan dan iliterasi yang menjadi akar permasalahan kasus kurang gizi.
\end{abstract}

Kata kunci: masalah gizi, balita, anemia, kualitas pelayanan kesehatan, Merauke.

*Korespondensi: Email: Iwibowo@seameo-recfon.org 


\section{PENDAHULUAN}

Peran penting gizi pada tumbuh kembang anak, serta kelangsungan hidup anak telah terdokumentasi dalam berbagai publikasi. Kekurangan gizi dapat menyebabkan gagal tumbuh (Allen 1994), keterbelakangan mental (Grantham-McGregor et al. 2000) dan lebih rentan terhadap penyakit (Rice et al. 2000). Hal ini mungkin berhubungan dengan peran gizi dalam proses metabolisme, kekebalan tubuh, dan nafsu makan (Golden 1995). Sementara itu, reversibilitas dari gangguan akibat kurang gizi tergantung pada tingkat keparahan, durasi, dan fase tumbuh kembang anak. Studi literatur mencatat bahwa secara total, 53\% dari semua kematian anak dapat dikaitkan dengan kondisi berat badan kurang (Black, Morris, \& Bryce 2003).

Seperti fenomena umum di negara berkembang, kasus kurang gizi pada anak-anak juga masih menjadi masalah kesehatan masyarakat di Indonesia. Hal tersebut disebabkan baik oleh kekurangan gizi makro maupun mikro. Menurut laporan Departemen Kesehatan (Riskesdas 2007), banyak balita di Indonesia yang pendek (36.8\%), berat badan kurang (18.4\%), dan kurus (13.6\%). Kabupaten Merauke, yang merupakan salah satu wilayah kerja World Vision Indonesia dan mitranya Wahana Visi Indonesia, merupakan salah satu kabupaten di Indonesia dengan tingkat permasalahan gizi pada balita yang cukup signifikan, antara lain: $26.4 \%$ pendek, $22 \%$ mempunyai berat badan kurang dan $14.8 \%$ kurus.

Intervensi gizi yang diperlukan untuk mengurangi masalah di atas harus efficacious, tepat sasaran, dan tepat dalam implementasinya. Jones, Steketee, Black, Bhutta, dan Morris (2003) telah memetakan beberapa intervensi yang feasible dan efficacious, yang jika diimplementasikan dengan efektif, dapat menurunkan tingkat kematian balita sekitar 65\%. Lebih jauh, Shrimpton et al. (2001), memaparkan bahwa gagal tumbuh akibat kekurangan gizi dapat terjadi sejak anak masih dalam kandungan atau setelah lahir. Oleh karenanya intervensi gizi harus dilakukan sedini mungkin sebelum dampak negatif dari kekurangan gizi menjadi irreversibel.

Agar efektif, intervensi harus sesuai dengan permasalahan dan kebutuhan kesehatan masyarakat. Oleh karenanya, penyusunan perencanaan program gizi dan kesehatan harus mengacu pada permasalahan dan kebutuhan kesehatan masyarakat serta kondisi sistem kesehatan yang ada. Survei ini dilakukan SEAMEO RECFON dalam rangka membantu World Vision Indonesia dan Wahana Visi Indonesia dalam merancang program gizi dan kesehatan di wilayah kerjanya di Kabupaten Merauke. Meskipun survei ini dilakukan hanya di wilayah kerja World Vision Indonesia dan Wahana Visi Indonesia, informasi yang diperoleh dapat juga digunakan oleh pihak lain yang berkepentingan dalam perancangan program gizi dan kesehatan di wilayah tersebut mengingat terbatasnya informasi tentang status kesehatan dan gizi balita di wilayah studi.

Penelitian ini dilakukan untuk menilai besaran masalah gizi dan kesehatan di Wilayah kerja World Vision Indonesia dan Wahana Visi Indonesia di Merauke serta faktor-faktor yang terkait.

\section{METODE}

\section{Desain, Tempat dan Waktu}

Penelitian menggunakan desain potong lintang (cross-sectional) dengan subjek penelitian adalah ibu balita, dilakukan dari bulan Oktober sampai Desember 2009 di tiga kecamatan wilayah kerja World Vision Indonesia dan Wahana Visi Indonesia di kabupaten Merauke yaitu: Kabupaten Semangga, Naukanjerai dan Malind.

Penelitian dilakukan setelah mendapatkan keterangan lolos kaji etik dari Panitia Tetap Penilai Etik Penelitian, Fakultas Kedokteran Universitas Indonesia.

\section{Jumlah dan Cara Pengambilan Contoh}

Sebanyak 30 posyandu dipilih secara acak dengan metode PPS (Proportional Probability Sampling) sebagai unit klaster di wilayah penelitian. Untuk mendapatkan kerangka sampling, dari setiap klaster dikumpulkan nama-nama balita dengan kriteria: 1) berumur 0-59 bulan 2) tidak menderita cacat bawaan. Jumlah contoh yang dibutuhkan adalah sebesar 535 balita yang dihitung berdasarkan rumus untuk mengestimasi proporsi balita dengan berat badan kurang (underweight) sebesar 22\%, dengan simpangan absolut $5 \%, a=0.05$, non response rate $10 \%$ dan design effect 2 . Penarikan contoh dari setiap klaster dilakukan secara acak dan proposional sesuai dengan besar klaster.

\section{Pengumpulan Data}

Pengumpulan data dilakukan oleh tim peneliti dengan cara interview, pengukuran antropometri, dan pengambilan sampel darah melalui ujung jari (finger prick). Semua aktivitas pengumpulan data dilakukan di pos tertentu yang telah ditentukan sebelumnya dengan mengumpulkan ibu dan balita yang terpilih. Kunjungan ke rumah responden dilakukan jika responden tidak dapat datang ke lokasi yang telah ditentukan. Informasi yang dikumpulkan melalui interview adalah demografi, keadaan sosial ekonomi, pola asuh, morbiditas anak dalam satu minggu terakhir, pengetahuan dan praktik ibu terkait dengan gizi dan kesehatan serta implementasi dan pemanfaatan program gizi dan kesehatan yang ada.

Sebelum aktivitas pengumpulan data, pelatihan untuk enumerator dilakukan oleh peneliti yang setelahnya diikuti oleh aktivitas pre-testing untuk 
menilai kualitas pelatihan dan kuisioner. Hasil pretesting digunakan sebagai masukan untuk merevisi kuisioner sehingga setiap pertanyaan dapat dipahami dengan persepsi yang sama baik oleh enumerator maupun responden.

Pelatihan antropometri untuk enumerator dilakukan oleh peneliti untuk meminimalkan intradan inter-obsever-error. Pengukuran antropometri (berat badan, panjang/tinggi badan) dilakukan oleh enumerator yang terlatih, dilakukan sebanyak 2 kali dengan selisih tidak lebih dari $0.2 \mathrm{~cm}$ untuk panjang/tinggi badan dan $0.2 \mathrm{~kg}$ untuk berat badan serta mengikuti prosedur standar WHO.

Pengukuran hemoglobin $(\mathrm{Hb})$ balita dilakukan oleh bidan puskesmas dan perawat rumah sakit yang sudah dilatih oleh peneliti. Pengambilan sampel darah melalui ujung jari (finger prick), kemudian diukur menggunakan metode cyanomethemoglobin dengan menggunakan alat portable hemocue. Kalibrasi hemocue dilakukan setiap hari sebelum pengumpulan data dengan menggunakan 3 jenis larutan hemotrol (low, medium dan high concentration) untuk menjamin keakuratan hasil pengukuran.

\section{Pengolahan dan Analisis Data}

Data hasil wawancara dan $\mathrm{Hb}$ diolah dengan menggunakan software SPSS versi 15 . Sebelum dilakukan analisis, uji normalitas dilakukan dengan menggunakan one-sample Kolmogorov-Smirrnov test. Software WHO anthro 2005 digunakan untuk mendapatkan nilai Z-skor atau indeks antropometri balita (BB/U, TB/U dan BB/TB). Status gizi balita kemudian diklasifikasi menggunakan referensi WHO 1995 dengan mengunakan ambang batas <-2 untuk kelompok gizi kurang (pendek, berat badan kurang, dan kurus). Status anemia balita ditentukan dengan menggunakan ambang batas menurut WHO tahun 2001: Anemia Ringan(10-10.9 g/dL), Anemia Sedang (7.0-9.9 g/dL) dan Anemia Berat $(<7.0 \mathrm{~g} / \mathrm{dL})$.

\section{HASIL DAN PEMBAHASAN}

Ibu-ibu yang menjadi responden sebagian besar berusia muda (20 tahunan), berasal dari keluarga inti yang beranggotakan rata-rata 5 orang, serta mempunyai maksimal 2 balita. Sebanyak $72 \%$ rumah tangga contoh tidak mempunyai pendapatan tetap. Masa pendidikan ibu dan bapak sebagian besar (70\%) kurang dari 9 tahun.

\section{Status gizi Balita}

Masalah kekurangan gizi pada balita, baik akut ataupun kronis yang terjadi di area survai menunjukkan masalah kesehatan masyarakat yang tergolong medium (Gambar 1). Proporsi dari tiga masalah kekurangan gizi didaerah penelitian, lebih rendah dan berada diluar selang kepercayaan (confidence interval) dari hasil RISKESDAS 2008, dimana ditemukan proporsi anak yang pendek, kurus dan berat badan kurang masing-masing $26.4 \%, 14.8 \%$ dan 22\% (Depkes 2008). Perbedaan ini terjadi dimungkinkan karena adanya perbedaan daerah sampling dan jumlah sampel. Pada penelitian ini, daerah yang dipilih adalah wilayah area dampingan WVI yang letaknya lebih banyak di area perkotaan.

Pada usia sangat dini ( $0-5$ bulan), prevalensi kekurangan gizi relatif rendah. Selama periode makanan pendamping ASI (6-11 bulan), prevalensi gizi buruk akut, yang diindikasikan oleh prevalensi balita kurus, meningkat sangat tajam sampai pada tingkat tinggi. Selanjutnya, pada usia 12-23 bulan, prevalensi kekurangan gizi kronis, seperti ditunjukkan oleh prevalensi balita pendek, mulai meningkat dari tingkat rendah ke tingkat menengah disertai penurunan prevalensi balita kurus. Karena sifatnya yang kronis, peningkatan prevalensi balita pendek cenderung stabil pada tingkat menengah, sementara prevalensi balita kurus berfluktuasi secara signifikan dalam kurun waktu lima tahun pertama.

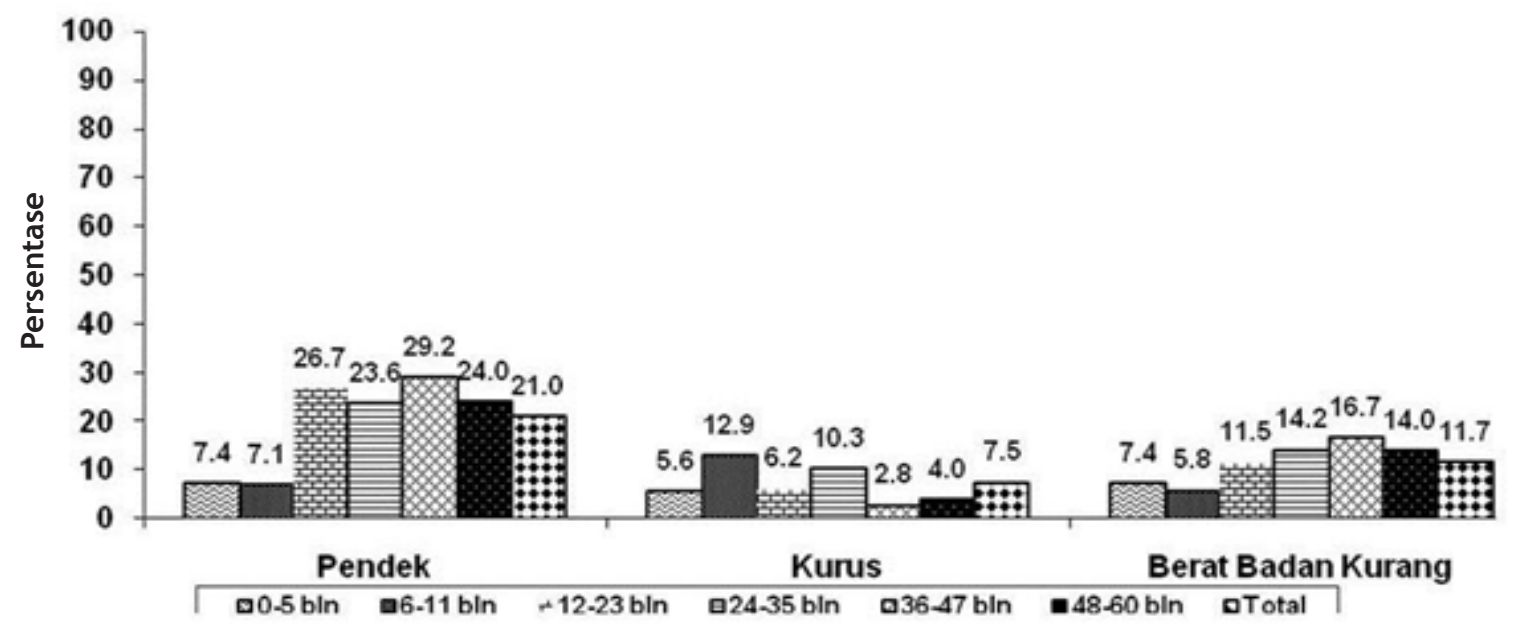

Gambar 1. Status Gizi Balita (Pendek, Kurus dan Berat Badan Kurang) 
Jenis, waktu, dan pola gagal tumbuh pada balita diilustrasikan dalam Gambar 2. Walaupun rata-rata balita terlahir dengan berat dan panjang badan yang tergolong normal (>-2 SD), tetapi berisiko kekurangan gizi karena rata-rata Z-skornya di bawah nilai median dari standar populasi (WHO growth standard 2005). Hal ini mengindikasikan terjadinya gagal tumbuh sejak dalam masa kandungan (Bhutta et al, 2008). Seiring dengan bertambahnya usia balita, proses gagal tumbuh menjadi semakin nyata terutama pada usia dua tahun pertama, diindikasikan oleh nilai TB/U Z-skor yang menurun tajam di bawah -1.00 Z-skor. Karena sifatnya yang kronis, meskipun TB/U Z-skor berfluktuasi pada kelompok umur di atas 2 tahun, akan tetapi, nilai rata-ratanya masih di bawah -1.00 Z-skor. Sebaliknya, pertumbuhan berat badan, seperti yang diindikasikan oleh BB/TB Z-skor, tetap konstan pada tahun pertama, meningkat dalam bulan-bulan berikutnya, dan kemudian stabil pada tingkat tertentu. Kondisi ini diasumsikan terkait dengan penurunan TB/U Zskor yang cukup tajam dibandingkan dengan penurunan $\mathrm{BB} / \mathrm{TB} \mathrm{Z}$-skor.

Kegagalan pertumbuhan balita setelah periode ASI ekslusif seperti yang ditemukan pada penelitian ini, umum terjadi dinegara berkembang, utamanya disebabkan oleh tidak optimalnya pemberian
MP ASI (Gibson RS et al. 1998; Dewey 2003). Selama periode MP ASI ini (6-24 Bulan), ASI menyediakan < $50 \%$ dari kebutuhan zat gizi besi, seng, sehingga kebutuhan zat gizi harus disediakan dari MPASI padat gizi.

Prevalensi balita yang menderita anemia $(\mathrm{Hb}$ level $<11.00 \mathrm{~g} / \mathrm{L}$ ) tergolong sangat tinggi pada semua umur, tanpa adanya pola spesifik menurut kelompok umur (Gambar 3).

Angka Kesakitan Balita dan Pola Pengasuhan Anak Hasil penelitian menemukan sebagian besar balita terjangkit penyakit saluran pernafasan (41\%), penyakit yang umum diderita balita di Indonesia. Jenis penyakit lainnya adalah demam $(21 \%)$, diare (10.3\%) serta demam berdarah (9.3\%).

Mayoritas balita diasuh oleh ibu kandung mereka sendiri $(93.2 \%$,), rata-rata ibu mengurus 2 sampai 3 anak. Jika ibu sedang mempunyai aktivitas lain, maka mayoritas rumah tangga contoh (75.5\%) mempunyai pengasuh pengganti, yang biasanya masih mempunyai hubungan keluarga.

\section{Praktik Pemberian Makan dan Menyusi Anak}

Meskipun menyusui adalah praktik umum di antara ibu dan diberikan berdasarkan permintaan anak, banyak dari mereka belum optimal melaku-

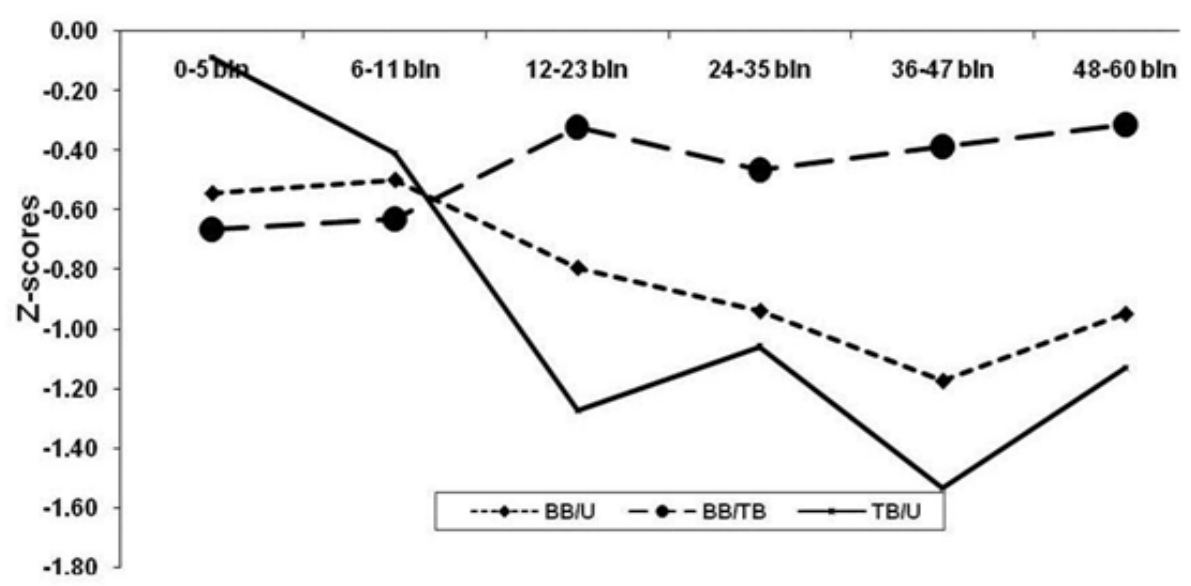

Gambar 2. Jenis, Waktu, dan Pola Gagal Tumbuh pada Balita di Area Survai

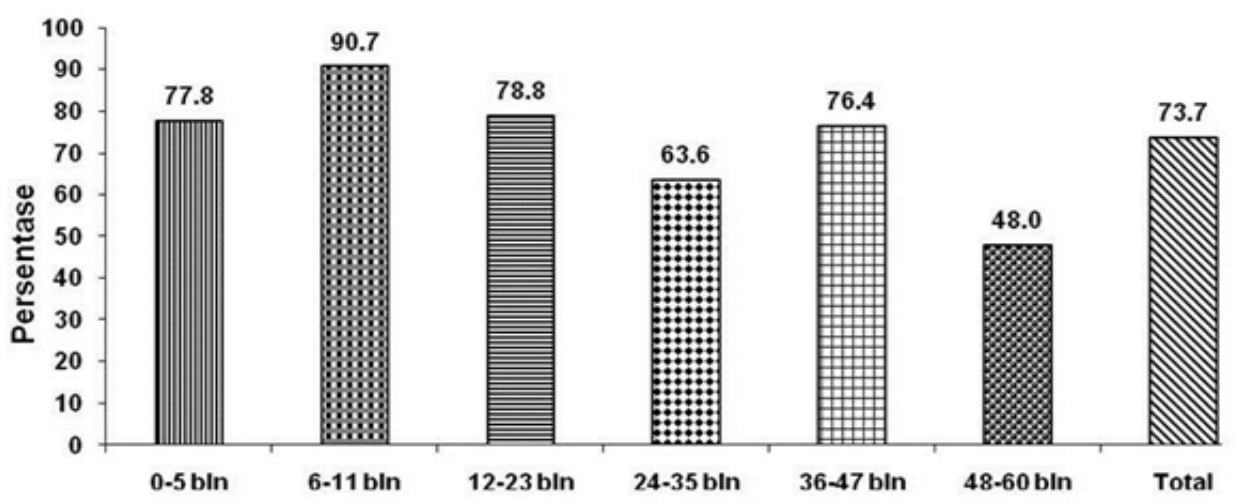

Gambar 3. Prevalensi Balita Penderita Anemia Berdasarkan Kelompok Umur 
kannya, seperti yang terindikasi dari rendahnya praktik inisiasi dini menyusui, ASI eksklusif enam bulan, serta menyusui yang dilanjutkan sampai 2 tahun.

Pemberian makanan pendamping ASI (MPASI) belum dipraktikkan secara benar oleh mayoritas ibu-ibu di daerah studi. MPASI diberikan baik terlalu dini (sebelum 6 bulan) atau bahkan terlambat (setelah 6 bulan). Mayoritas ibu-ibu cenderung untuk memperkenalkan MP ASI terlalu dini dibandingkan dengan pengenalan MP ASI tepat waktu dan atau terlambat. Setelah diperkenalkan, ada juga kecenderungan untuk memberi makan anak dalam secara teratur selama 2-4 kali dalam sehari.

\section{Perawatan Kesehatan dan Penggunaan Pelayanan}

Perawatan di rumah untuk diare digunakan dalam survei ini sebagai salah satu indikator kesehatan. Untuk mendapatkan informasi ini, kami mengajukan pertanyaan ini hanya untuk ibu-ibu yang balitanya menderita diare di masa lalu (38.4\%). Di antara ibu-ibu, sebagian kecil dari mereka tidak memberikan pengobatan untuk anak mereka dan hanya $64.5 \%$ dari mereka diberikan larutan rehidrasi oral (oralit). Meski sebagian besar ibu memberikan oralit untuk anak-anak mereka saat diare, sepertiga dari mereka juga memberikan ramuan tradisional (daun jambu yang direbus dengan air matang, teh kental) atau obat modern (anti-diare/antibiotik).

Secara umum, pemberian makan anak selama diare tidak dipraktikkan dengan benar oleh banyak ibu. Pada anak kelompok umur <6 bulan, hanya ada 47.6\% ibu mempraktikkan cara pemberian makan dengan benar, yaitu memberikan ASI saja, sementara pada anak kelompok usia yang lebih tua hanya $37.8 \%$ ibu-ibu mempraktikkan cara pemberian makan dengan benar, yaitu memberi makan balita seperti biasa.

Program imunisasi yang dilaksanakan di daerah penelitian, dinilai berdasarkan perkiraan caku- pan program dengan menghitung proporsi balita yang menerima imunisasi lengkap. Untuk tujuan ini, perhitungan hanya terfokus pada anak-anak berusia $\geq 1$ tahun, dengan asumsi bahwa mereka seharusnya sudah mendapatkan seluruh rangkaian imunisasi jika rekomendasi itu diikuti. Hasil penelitian menunjukkan bahwa ada 98\% dari anak-anak telah diimunisasi dan mayoritas dari mereka memiliki catatan imunisasi lengkap, meskipun ada beberapa dari mereka memiliki catatan tidak baik atau tidak lengkap. Masalah ini terjadi karena tiga sebab: ibu kehilangan catatan, staf kesehatan lupa untuk mengisi formulir, atau ibu lupa membawa formulir selama sesi imunisasi.

Cakupan imunisasi tergolong cukup tinggi (82.1\%) meskipun belum mencapai cakupan universal (90\%). Agar lebih akurat, informasi ini diekstrak dari data khusus anak-anak berusia $\geq 1$ tahun yang telah diimunisasi dan memiliki catatan. Bila dilihat dari jenis vaksin, kita juga mengamati bahwa cakupan dari setiap jenis imunisasi tergolong tinggi. Namun, terdapat pola distribusi proporsi yang sama ditemukan pada imunisasi serial seperti imunisasi DPT, hepatitis, dan polio, di mana proporsi terus menurun di setiap imunisasi ulang.

\section{Pemanfaatan Pelayanan Kesehatan di Posyandu \\ Pemanfaatan pelayanan kesehatan di posyan-} du tergolong tinggi dengan berbagai tingkat kebutuhan yang mendasari niat mereka untuk menggunakan layanan tersebut. Penimbangan berat badan anak secara rutin adalah salah satu kegiatan paling umum yang dicari ibu di posyandu karena mereka semua percaya pada pentingnya Program Pemantauan Pertumbuhan yang harus disampaikan secara rutin secara bulanan.

Meskipun cakupan program imunisasi termasuk tinggi, hanya sekitar setengah dari balita diimunisasi di posyandu. Kami juga mengamati sejumlah ibu-ibu mengunjungi posyandu untuk mendapatkan

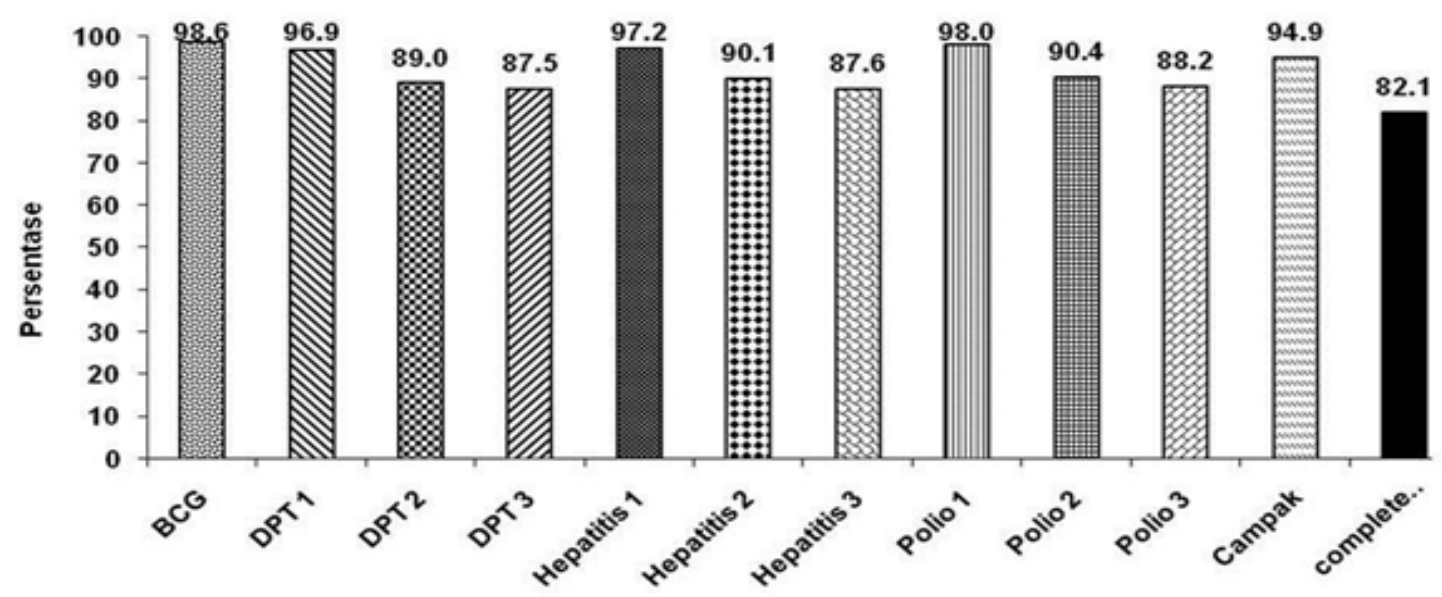

Gambar 4. Cakupan Imunisasi Balita 
pengobatan, makanan tambahan atau suplemen untuk anak mereka. Namun, tidak satupun dari ibu mengatakan bahwa kunjungan mereka ke posyandu adalah untuk konsultasi/mendapatkan penyuluhan.

Pemanfaatan program di posyandu yang tinggi tidak menjamin kehadiran rutin ibu di pos yandu seperti yang kita temukan bahwa sebanyak $22 \%$ dari ibu tidak rutin datang ke posyandu dalam waktu tiga bulan sebelum wawancara. Berdasarkan laporan ibu, mereka melewatkan sesi posyandu dikarenakan: ibu tidak punya waktu untuk pergi ke posyandu, ibu/anak sakit, ibu/anak berada jauh dari desa, atau ibu lupa jadwal posyandu sesi. Di antara mereka yang rutin datang ke posyandu, sebagian besar dari mereka memiliki catatan layanan kesehatan yang lengkap.

Gambar 5 menunjukkan dua informasi penting terkait dengan pelaksanaan program vitamin A di daerah studi. Pertama, kita dapat mengamati adanya mistargetting kapsul. Berdasarkan rekomendasi, vitamin A dosis tinggi hanya akan dibagikan kepada anak usia $\geq 6$ bulan, tapi temuan kami menunjukkan bahwa beberapa dari penerima manfaat program masih bayi muda berusia $<6$ bulan. Kedua, kita bisa mengasumsikan bahwa program itu tidak optimal dilaksanakan seperti yang ditunjukkan oleh cakupan relatif rendah $(61 \%)$ dibandingkan dengan cakupan data rutin Dinas Kesehatan setempat.

Pelaksanaan program vitamin A di daerah studi belum dilakukan secara optimal. Kami menemukan sekitar setengah dari kelompok usia yang lebih muda (51.9\%) menerima vitamin A dengan dosis terlalu tinggi, sementara sebanyak $16.7 \%$ anak yang lebih tua menerima vitamin A dengan dosis terlalu rendah.

\section{Jenis Pelayanan Kesehatan Digunakan Selama Minggu Terakhir \\ Hampir semua ibu melaporkan bahwa mereka}

biasanya pergi ke petugas kesehatan ketika anak mereka jatuh sakit, sedikit dari mereka melakukan pengobatan sendiri dan hanya seorang ibu pergi ke dukun. Di antara mereka yang pergi ke tenaga kesehatan, proporsi terbesar pergi ke tenaga kesehatan di posyandu/pustu/puskesmas, sedangkan sisanya ke rumah sakit, praktik pribadi dokter, atau tempat lain seperti seminari atau pos militer.

Alasan untuk memanfaatkan pelayanan kesehatan bervariasi dan berkisar dari satu sampai maksimal tiga alasan. Sekitar dua pertiga responden kami hanya memiliki satu alasan memilih layanan kesehatan tertentu di mana setengah dari mereka mengatakan "kualitas" di luar alasan lain, sementara setengah yang lain menyebutkan "aksesibilitas”, keterjangkauan biaya, dan alasan lainnya.

\section{Pengetahuan Gizi dan Kesehatan ibu Balita}

Secara umum (> 40\%), pengetahuan ibu balita tergolong masih kurang (Gambar 6). Tingkat pengetahuan ibu dalam hal ASI dan MPASI, makanan sumber zat besi dan vitamin A, pemantauan pertumbuhan, program vitamin A, perawatan diare dan imunisasi tergolong masih memprihatinkan.

Dari hasil survei, diperoleh beberapa informasi penting yang dapat dan seharusnya digunakan minimalnya untuk tiga tujuan, yaitu: [1] Memilih pendekatan yang diperlukan dan berpotensi dapat mengatasi masalah gizi/kesehatan yang ada. [2] Mencari tahu apakah program yang sudah dilaksanakan telah mencapai hasil yang dimaksudkan. [3] Mengarahkan intervensi-intervensi terpilih, baik baru atau yang sudah ada, agar tepat sasaran.

Untuk mengatasi permasalahan gizi di wilayah studi, maka intervensi harus bersifat efficacious dan mampu laksana sesuai konteks lokal. Dalam hal ini dibutuhkan minimalnya tiga informasi yang esensial untuk pemilihan intervensi, yaitu: [1] masalah gizi/kesehatan yang ada dan besarannya, [2]

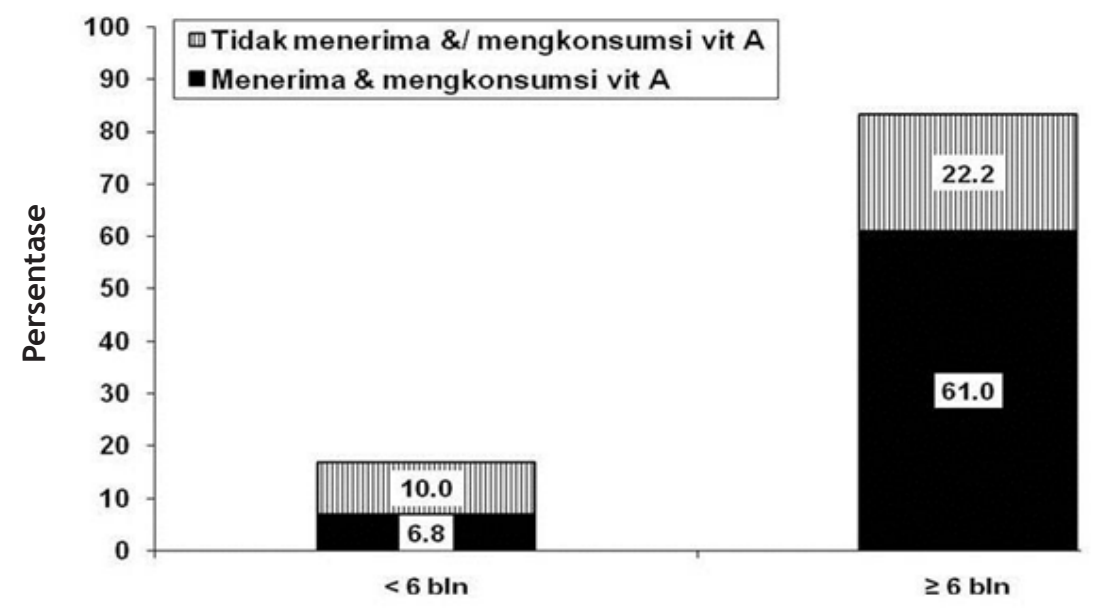

Gambar 5. Cakupan Suplementasi Vitamin A Balita 


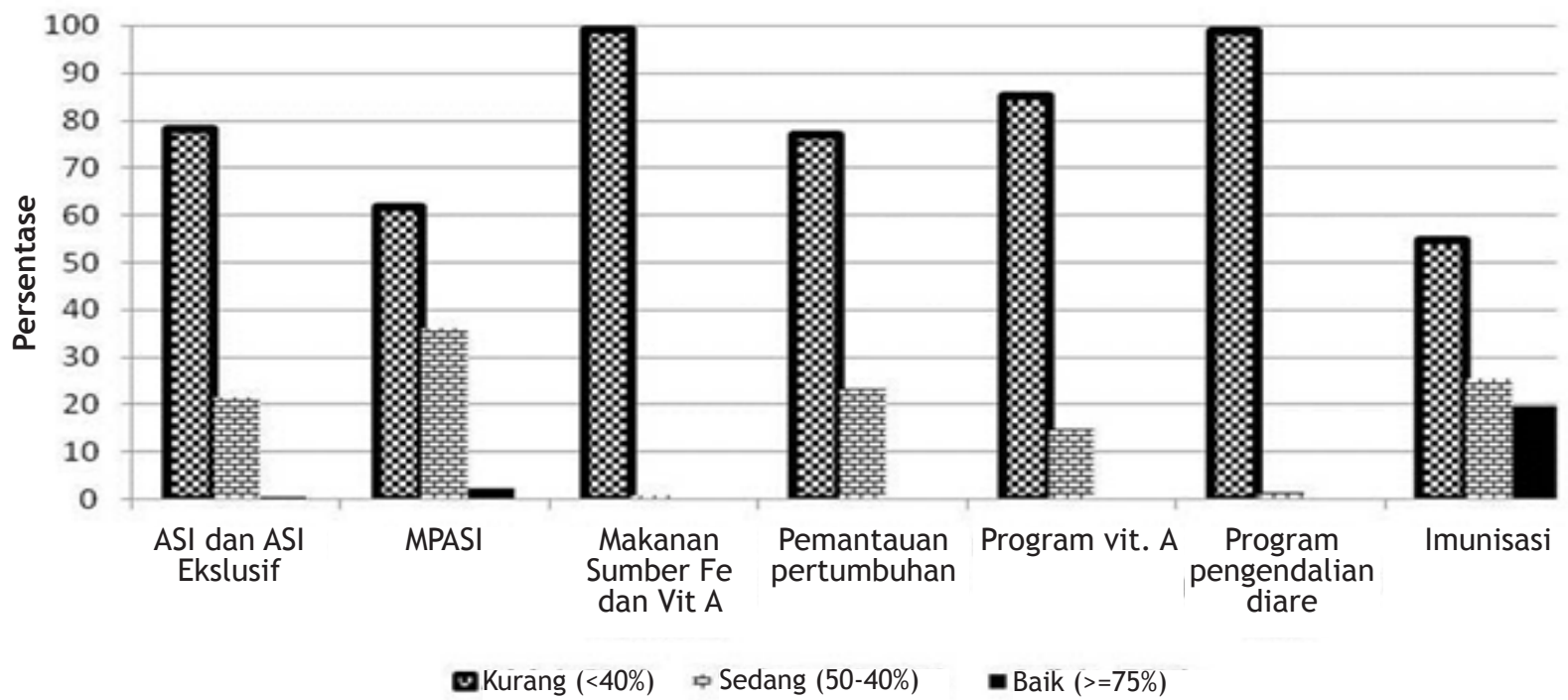

Gambar 6. Pengetahuan Gizi dan Kesehatan Ibu Balita

intervensi apa saja yang telah terbukti efficacious untuk mengatasi masalah gizi/kesehatan tersebut, dan [3] kapasitas sistem kesehatan lokal. Di wilayah penelitian, masalah kekurangan gizi (misalnya anemia, kurus, pendek, berat badan kurang) pada balita masih merupakan masalah kesehatan yang cukup signifikan seperti yang terindikasi oleh data prevalensi yang ada. Karena masalah kekurangan gizi bersifat multidimensional, maka pendekatan yang dilakukan idealnya harus dalam bentuk "paket program", yaitu gabungan beberapa program yang diimplementasikan secara terintegrasi. Berdasarkan kajian pustaka, intervensi-intervensi yang efficacious dapat dengan mudah diidentifikasi. Akan tetapi, informasi tentang kapasitas sistem kesehatan juga harus ada sebagai acuan penilaian dan seleksi untuk intervensi yang mampu laksana. Jones et al. (2003) merekomendasikan beberapa intervensi yang terbukti efektif untuk mengatasi masalah kekurangan gizi balita seperti: promosi praktik pemberian ASI dan makan pendamping yang tepat, suplementasi vitamin A dosis tinggi, imunisasi, dan promosi manajemen terpadu balita sakit. Selain itu, sistem pemantauan pertumbuhan anak untuk deteksi dini kejadian gizi buruk beserta sistem rujukannya juga harus terintegrasi ke dalam "paket program".

Meski intervensi atau program kesehatan dan gizi yang disebutkan di atas telah diimplementasikan di wilayah penelitian, hasil survei menunjukkan bahwa program-program tersebut belum dapat mengatasi permasalahan yang terjadi. Fakta ini harus diinterpretasikan secara hati-hati mengingat tidak adanya informasi tentang kapasitas sistem kesehatan dalam mengimplementasikan program. Agar efektif, intervensi yang efficacious harus diimplementasikan secara benar, tepat sasaran, de- ngan cakupan universal (minimal 90\%), dan diterima dengan baik oleh masyarakat. Intervensi yang efficacious adalah intervensi yang sesuai kebutuhan dan tepat sasaran. Sementara, kesuksesan implementasi program (cost-effective) sangat tergantung pada perancangan program dan kapasitas sistem kesehatan. Sesuai tujuannya, survei ini hanya difokuskan untuk memperoleh informasi tentang masalah gizi dan kesehatan, besaran masalah, outcome program (cakupan program dan pengetahuan dan praktik ibu balita terkait gizi dan kesehatan anak), dan sedikit informasi tentang penerimaan masyarakat terhadap program gizi dan kesehatan. Maka, dengan mempertimbangkan argumentasi di atas, hasil survei, belum dapat digunakan untuk menarik suatu kesimpulan tentang efektivitas program yang ada, meskipun capaian program terbukti belum optimal. Asumsinya bahwa program yang belum terimplementasi dengan benar bukan berarti program tersebut tidak efektif.

Seperti telah disebutkan di atas bahwa efficacy program (bukan efektivitas) tidak hanya ditentukan oleh keselarasan dengan kebutuhan, tetapi juga penargetannya (apakah tepat sasaran atau tidak). Hasil survei ini dapat digunakan untuk menentukan kelompok sasaran program dengan tepat yang teridentifikasi dari pola distribusi masalah gizi untuk menentukan: kapan dan seberapa responsif kelompok tersebut terhadap intervensi yang diberikan. Misalnya, meski masalah kekurangan gizi umum terjadi di kelompok balita yang disurvei, bukan berarti bahwa semua balita harus menerima "paket program" yang sama. Beberapa masalah gizi seperti kurus, kurang berat badan, dan pendek memiliki pola distribusi yang berbeda dan spesifik berdasarkan umur, seperti yang juga ditemukan oleh Shrimpton (2001). Agar cost - effective, beberapa program sebaiknya hanya diberikan pada kelompok sasaran 
yang masih responsif terhadap intervensi (responsive period). Di sisi lain, tidak ada pola distribusi khusus yang ditemukan pada masalah kesehatan/ gizi lainnya seperti anemia dan kesakitan pada balita. Dalam hal ini, intervensi terkait masalah tersebut dapat dan harus diarahkan kepada semua balita.

\section{KESIMPULAN}

Penelitian ini menyimpulkan bahwa kasus kurang gizi masih tergolong permasalahan kesehatan masyarakat. Sebagai rekomendasi, disarankan untuk menjalankan dua strategi secara paralel yaitu 1) dengan mengoptimalkan program-program yang sudah berjalan seperti pemantauan status gizi di posyandu, program suplementasi vitamin A, Pencegahan dan pengendalian penyakit, dan promosi pemberian ASI dan MP ASI dengan didahului oleh review sistem kesehatan agar diketahui komponen sistem yang mana yang perlu penguatan, 2) melalui kerjasama lintas sektor serta melibatkan partisipasi masyarakat bersama-sama dengan pemerintah untuk mengentaskan kemiskinan dan iliterasi yang menjadi akar permasalahan kasus kurang gizi.

\section{UCAPAN TERIMA KASIH}

Ucapan terima kasih kami sampaikan kepada World Vision Indonesia yang telah mendanai kegiatan penelitian dan Wahana Visi Indonesia yang mendukung pelaksanaan penelitian ini di lapangan.

\section{DAFTAR PUSTAKA}

Allen LH. 1994. Nutritional influences on linear growth: a general review. Eur J Clin Nutr, 48(Suppl 1), S75-S89

Bhutta ZA, Ahmed T, Black R, et al. 2008. Maternal and child undernutrition 3: What works? Interventions for maternal and child undernutrition and survival. The Lancet, 371, 417-
440.

Black RE, Morris SS, \& Bryce J. 2003. Where and why are 10 million children dying every year? The Lancet, 361(9376), 2226-34.

Departemen Kesehatan Republik Indonesia (DepkesRI). 2008. Riset Kesehatan Dasar 2007. Badan Penelitian dan Pengembangan Kesehatan Depkes RI, Jakarta.

. 2008. Badan Penelitian dan Pengembangan Kesehatan Depkes RI. Laporan Riset Kesehatan Dasar provinsi Papua 2008. Jakarta.

Dewey KG \& Brown KH. 2003. Update on technical issues concerning complementary feeding of young children in developing countries and implications for intervention programs. Food Nutr Bull, 24, 5-28

Gibson RS, Ferguson EL, \& Lehrfeld J. 1998. Complementary foods for infant feeding in developing countries: their nutrient adequacy and improvement. Eur J Clin Nutr, 52, 764-70.

Golden MHN. 1995. Specific Deficiencies versus Growth Failure: Type I and Type II nutrients. United Nations (ACC/SCN). WHO, Geneva, Switzerland. SCN News, 12, 10-14.

Grantham-McGregor SM, Walker SP, \& Chang S. Nutritional deficiencies and later behavioural development. Proc Nutr Soc, 59, 47-54.

Jones G, Steketee RW, Black RE, Bhutta ZA, \& Morris SS. How many child deaths can we prevent this year? The Lancet, 362, 65-71.

Shrimpton R, Victora CG, de Onis M, Lima RC, Blossner M, \& Clugston G. 2001. Worldwide timing of growth faltering: implications for nutritional interventions. Pediatrics, 107, E75.

WHO. 1995. Physical status: the use and interpretation of anthropometry. WHO, Geneva, Switzerland.

WHO/UNICEF/UNU. 2001. Iron Deficiency anaemia, assessment, prevention and control: a guide for program manager. WHO, Geneva, Switzerland. 